\title{
Parametric Experiments on Palladio's 5 by 3 Villas
}

\author{
Roberta Spallone $^{1}$ (D) Michele Calvano ${ }^{1}$
}

Accepted: 21 January 2022 / Published online: 15 February 2022

(c) The Author(s) 2022

\begin{abstract}
This paper investigates and describes the parametric reconstruction of Palladio's villas, using his treatise, I Quattro libri dell'architettura, as the primary source. The process starts with an extensive comparison of Palladio's rooms' ratios, the compositional rules of the villas' plans, and the digital creation of parametric architectural elements. Finally, the process of parametric construction on three selected case studies of 5 by 3 villas-Villa Poiana, Villa Zeno, and Villa Thiene in Cicogna-is undertaken. The developed instrument offers an experimental laboratory in which different hypotheses of integration by the authors, or other scholars with reference to the sources, could be tested.
\end{abstract}

Keywords Andrea Palladio · I Quattro libri dell'architettura · Palladio's villas · Harmonic ratios $\cdot$ Architectural elements parametrization $\cdot$ Reconstructive parametric modelling

\section{Introduction}

Several scholars from the mid-twentieth century have highlighted traces of parametric thinking in Palladio's designs, mainly with focus on his villas. The availability of digital parametric tools today has provided the opportunity for this paper to develop an instrument to interpret the compositional logic of the villas Palladio describes in Book II of the treatise I Quattro libri dell'architettura (1570) and to rebuild them virtually.

Two lines of research about Palladio's designs have been summarized by Tikhonova (2019: 362-363); the first focuses on Palladio's theory of proportions while the second is on formulas and rules for parametric generation of the

Roberta Spallone

roberta.spallone@polito.it

Michele Calvano

architetto.calvano@gmail.com

1 Department of Architecture and Design, Politecnico Di Torino, Viale Mattioli 39, 10125 Turin, Italy 
villa's plans. Both lines inspired the analysis phase of this research, which aims to overcome the two-dimensional survey by creating three-dimensional (3D) parametric models through the combination of Visual Programming Language and Building Information Modelling (VPL and BIM, respectively) tools. Previous research by the authors (Spallone and Calvano 2019) undertook a preliminarily investigation of the roots of parametric thinking in Palladio's villas using his treatise as a source, and referring mainly to the studies of Wittkower (1949) and Stiny and Mitchell (1978). In the current paper, the analyses of the geometric and proportional characteristics of the architectural elements, the compositional principles, and the proportional criteria that include the ratios described in the treatise and those widespread in Renaissance culture in all the plans of block villas, are presented. These analyses are aimed at exploring the possibilities of parametric modelling in the 3D digital reconstruction of the villas' design, while taking into account the limited data on heights given in the treatise. The analysis has been realized digitally by creating the vocabulary of architectural elements defined by Palladio in Book I, and experimenting with the process of parametric construction on three selected case studies of 5 by 3 villas, such as Villa Poiana, Villa Zeno, and Villa Thiene in Cicogna (Fig. 1).
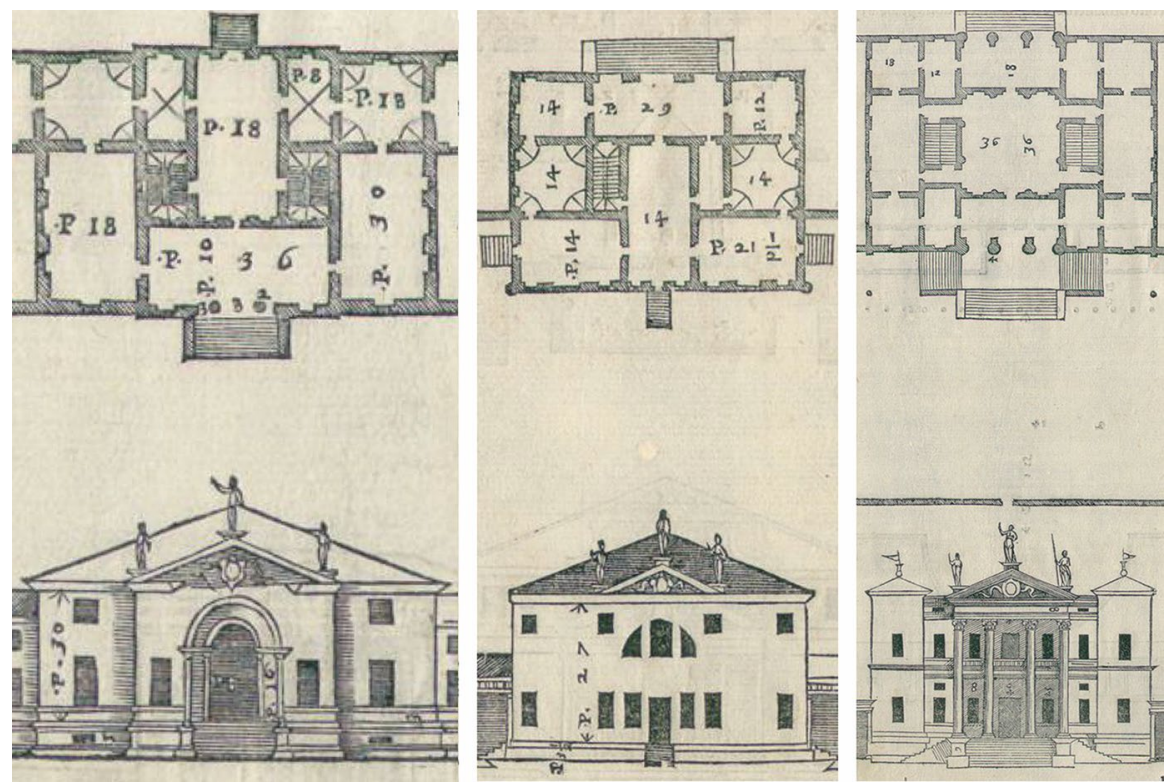

Fig. 1 Andrea Palladio, excerpts of villas Poiana, Zeno, and Thiene in Cicogna, plans and elevations. Source: Palladio 1570: 58, 49, 62 
Fig. 2 Palladio's seven types of rooms

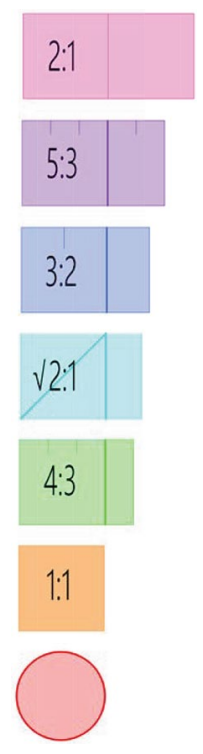

\section{Architectural Principles and Compositional Criteria in Book I}

The analysis phase incorporates the data from Book I on room ratios and heights, architectural element geometry and proportions, and compositional criteria with the description of the villas in Book II. In Book I, Palladio sets out "seven types of room that are the most beautiful and well-proportioned and turn out better: they can be made circular, though these are rare; or square; or their length will equal the diagonal of the square of the breadth; or a square and a third; or a square and a half; or a square and two-thirds; or two squares" (Palladio 1997: 57). That is, apart from the circle, he defines six rectangles of ratios $1 / 1, \sqrt{ } 2 / 1$, 4/3,3/2, 5/3, and 2/1 (Fig. 2), useful for loggias, entrances, halls, and rooms.

Palladio also suggests the height of rooms with a flat ceiling and three methods to effectively determine the heights of vaulted rooms: (1) arithmetic, (2) geometric, and (3) harmonic means of their lengths and breadths (Fig. 3). As Mitrović observes, Palladio used flat ceilings mainly in the upper stories, and preferred vaulted ceilings for ground floor rooms (1990: 280). Nevertheless, Palladio says that other heights for vaults that do not come under any rule exist (Palladio 1997: 59). Perhaps this possibility could explain the rather limited use of his heights' proportional method in villas. Concerning this issue, Mitrović hypothesized the Condition on the Concordance of Heights (1990), seeking to explain Palladio's combination of preferred room ratios, and the use of a columnar system (2004: 65). In addition, Palladio describes a real vocabulary of architectural elements. He specifies the geometrical shapes of the vaults and their rises in relation with the seven room's plans, and the dimensions of doors, windows, and staircases. 
Seven vaults are superimposed on plans which, in sequence, have the seven ideal forms described previously. The association between plan and type of vault developed, as described in the circular plan, is covered by a dome, the plan in ratio $1: 1$ by a sail vault, the rectangular $4: 3$ by a cross vault, the $\sqrt{ } 2 / 1$ and $3: 2$ by a coved vault (that is, a depressed vault with a horizontal top or central compartment) whose rise is a third of the width of the room, the 5:3 by a lunette vault, and the $2: 1$ by a barrel vault (Fig. 4 ).

A particularly significant element is the staircase. Palladio warns about the difficulty of locating the staircase so that it does not interfere with the spatial organization of the building (Mitrović 2004: 73) and states that for this reason, it is necessary to find its location at the beginning of the design phase.

The principle of symmetry dictates the design criteria and the resulting distributive system of the buildings. Indeed, as Palladio affirms, "[]Rooms must be distributed at either side of the entrance and the hall, and one must ensure that those on the right correspond and are equal to those on the left so that the building will be the same on one side as on the other and the walls will take the weight of the roof equally" (Palladio 1997: 57). Moreover, in the plates, the so-called enfilade, which rules the alignment of openings and internal doors, is evident (Kühbhacher 1990: 176).

From this background it is apparent that the proportions of the rooms, in addition to the elements of the architecture, are linked by a system of relationships analogous to that implemented by Palladio for the orders and that can further support the validity of reading his work in parametric terms.

\section{Room Ratios in the Villas}

This research uses the treatise as the main documental source. Palladio's book consists of texts and plates representing the buildings by ground floor plan and main façade. The choice to refer to the treatise was made after considering that it was published some years after the construction of most of the villas, and considering the opinions of several scholars who argue that the book represents Palladio's design theory (among others, Moretti 1952: 107; Wassell 1999: 126; Sass 2001: 2013; García-Salgado 2008: 269). The survey drawings by Bertotti Scamozzi (1796) and the recent ones by A. Soltan, E. Soltan, and M. Zocconi on behalf of CISA A. Palladio (1979) have been considered only to confirm the data assumed from the treatise, keeping in mind the gap between design and construction.

Among the 24 villas described in the treatise, 19 have central block plans, which are dedicated to the owners' courtly residence and are suitable for the present analysis. This analysis starts from the 19 plans and highlights both the harmonic and geometric ratios that rule the shape of the rooms and the compositional grids as the basis of 3D parametric modelling. Moreover, the entrance and distribution system (loggia, vestibule, hall, staircase) that allows vertical access to the building and therefore the passage from 2 to 3D analysis has been studied. The 19 analyzed plans encompass villas designed over a period of about 30 years, dated according to 
Fig. 3 Arithmetic, geometric, and harmonic methods for the heights of rooms. Source: Palladio 1570: 53, 54

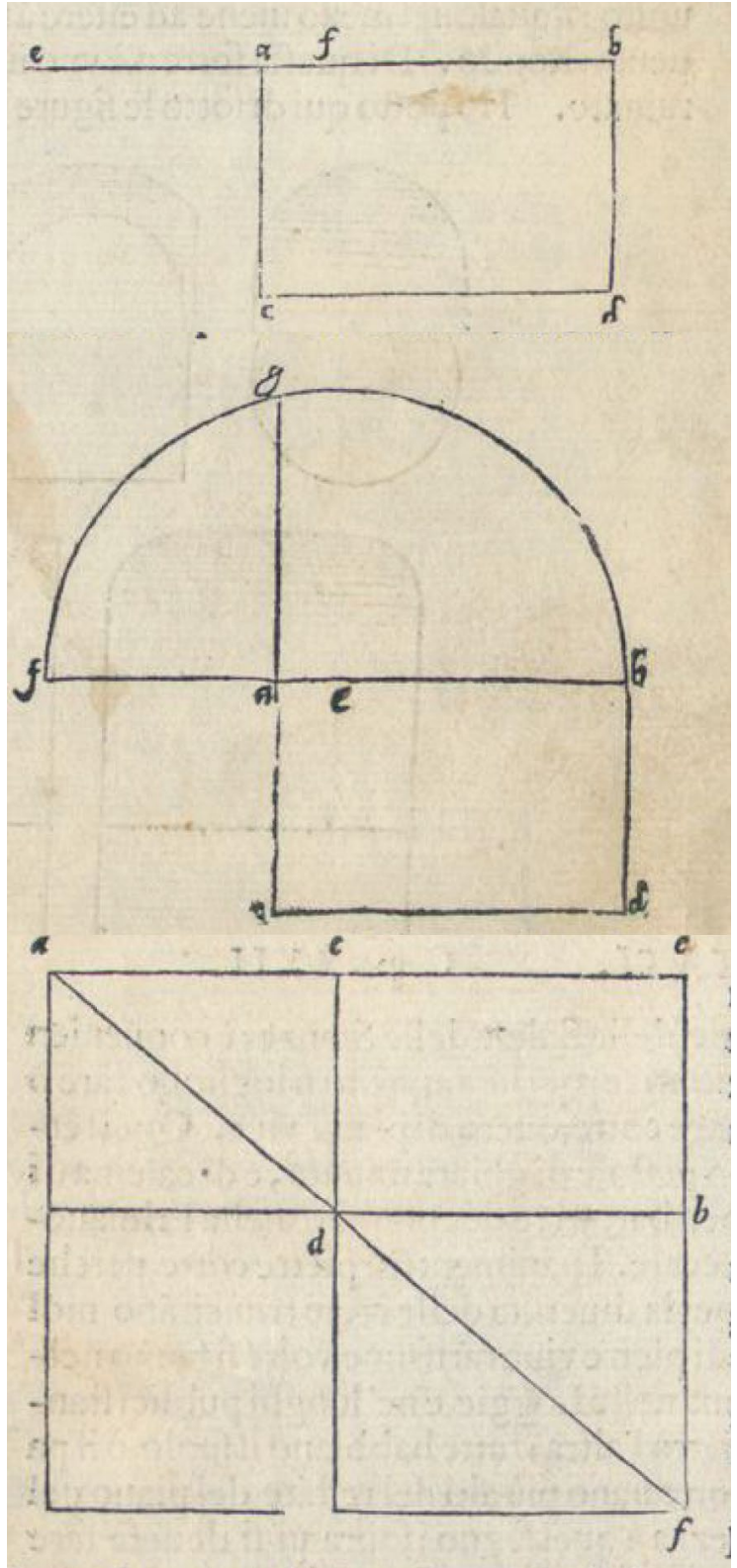

the CISA A. Palladio website. Among them, only five present biaxial symmetries in their plans (Fig. 5).

The prevailing grid is 5 by 3 and characterizes 13 villas, the remaining six are organized on a 3 by 3 grid. The hall is always arranged along the axis of symmetry; in three cases it has its center at the intersection of the two axes of symmetry. 


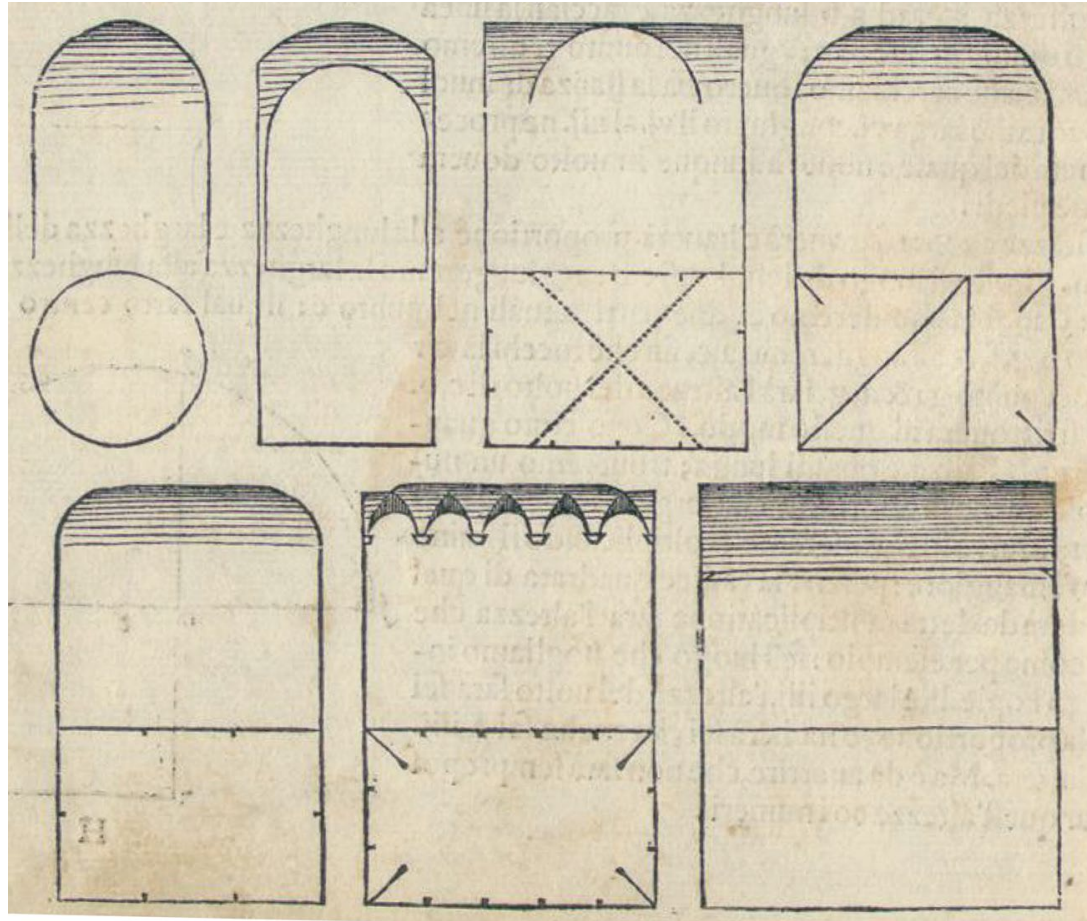

Fig. 4 Palladio's types of vaults. Source: Palladio 1570: 54

The analysis of the plans incorporated fundamental research by Wittkower (1944, 1945, 1949). The eleven diagrams of Palladian villas, that were recognized and compared by him as different statements of the same geometrical formula, form the starting point of this phase of the work. The woodcut plans of the 19 villas have been scaled using the dimensions found in the treatise and the Vicentine feet as measurement units. The Vicentine foot has been assumed as equal to $0.357 \mathrm{~m}$ (March 2001: 101), keeping in mind the observations of Mitrović (2004: 36 and 206, note 6) about the different values assigned by scholars. This operation enabled the discovery of some inconsistencies between text and images and allowed for addressing the issue of the constant thickness of walls that has been interpreted as an idealized thickness, which is equal to zero. An elementary and decisive piece of evidence in support of the choice to hypothesize the thickness of the walls to be equal to zero (that has not been highlighted by scholars) consists of the verification of the measurements thanks to the projective correspondence. In fact, the sum of the widths of the rooms and the height of the elevation from the ground floor to the cornice, often written by Palladio on the drawing, allow one to verify this hypothesis on the elevation drawing. Therefore, according to Rosci (1966: 61) the designs of Palladio include half of the wall thickness in the written dimensions; this inclusion has been assumed as criterion for drafting the interpretative plans. Moreover, Kühbacher (1990: 169) observes that Palladio assigns the walls the same thickness regardless of the real structure. More recently, Benelli (2008: 51) recalls Wittkower's analytical drawings probably deduced from Palladio's own way of drawing 


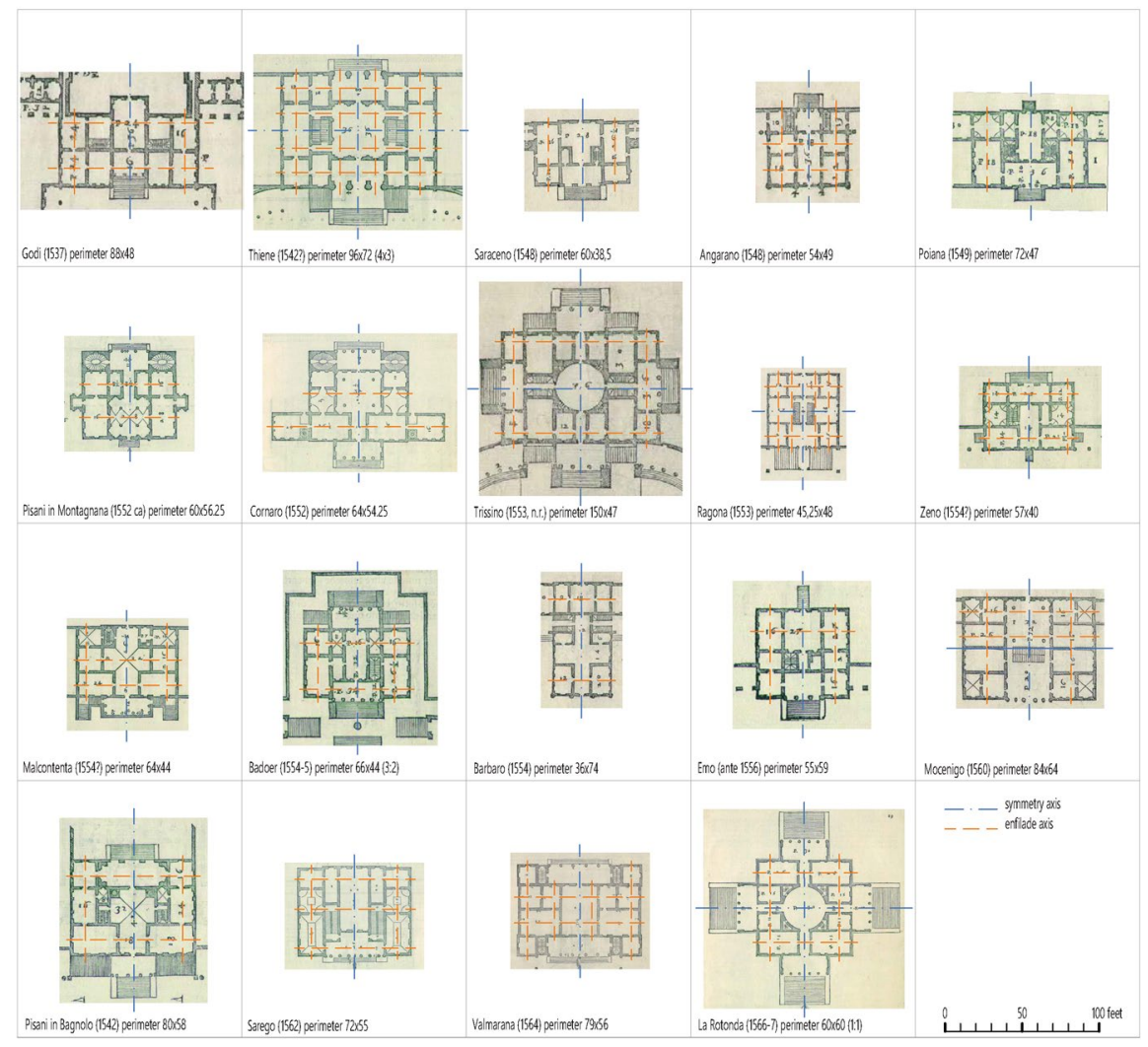

Fig. 5 Compositional criteria in the 19 central block villas: symmetry (in blue) and enfilade (in orange). Source: Palladio 1570

in which the already idealized wall thicknesses that appear in the illustrations of the treatise are reduced to wire-frame as in the drawings kept at the RIBA. These opinions seem to be more convincing than those of Howard and Longair (1982: 128-129), who try to calculate the thickness of the walls by relating the dimensions of each room with the overall external dimensions so that they are in a harmonic relationship. Instead, Stiny and Mitchell (1978) establish the thickness of the walls to be homogeneous and equal to two feet and add this measurement to that of the rooms.

For this process the ratios between the sides of each room are graphically highlighted. The rooms' dimensions and the percentage of rooms having harmonic ratios have been tabulated by scholars (Howard and Longair 1982; Mitrović 1990, 2004). The graphical representation by the present authors adds the immediate synoptic view, the dimensional comparison, and the recognition of topological relationships between the rooms to those tables. The measurements not written in the drawings and not obtainable through the text have been deduced as follows: (1) thanks to symmetry, walls alignment, sum and difference between the measures of rooms side-by-side, and (2) through graphic analysis, noting the rooms ratios 
(overwritten measurements in square brackets). Finally, evident discrepancies between the printed measure and the dimensions surveyed on the drawing were considered typographical errors (measures indicated with asterisks).

In the first phase, only the six canonical ratios $(1: 1,4: 3, \sqrt{ } 2: 1,3: 2,5: 3,2: 1)$ are demonstrated (Fig. 6), keeping in mind that the scholars have noted the presence of other meaningful ratios in Palladio's plates, i.e., the harmonic ratios from the Albertian theory widespread in the Renaissance culture as "polyphony of proportions" (Wittkower 1945: 78-80) and the geometric ratios derived from cube (Mitrović 1999 and 2004: 65-70, March 2001). In Fig. 7, some of Alberti's ratios, $4: 9,3: 8$, and 1:3, have been recognized in the rooms of four among the 19 villas.

In Fig. 8 the cube-derived ratios $\sqrt{ } 3: 1, \sqrt[3]{2^{2}}: 1$, and $\sqrt[3]{2}: 1$, recognized by Mitrović in the plans of the treatise, are illustrated in addition to the Palladian six ratios. Eight among the 19 villas present these ratios. The identification of harmonic and geometric ratios and in general the lengths and breadth of the rooms is the first step towards 3D reconstructions using several parameters: (1) the metric relationships between plan and elevation obtained through the few written vertical measures, (2) the rare indications about the proportions between the sides of the rooms and their height, (3) the geometries of the rooms' vaults that should have an equal height as Palladio establishes (1570: 54), and (4) the measures and proportions of architectural elements, such as doors, windows, and stairs.

\section{Plan Grids from 2D Compositional Rules to 3D Design}

The study of Wittkower, culminating in his drawing of 11 villas' patterns as the result of the same geometrical formula, and the more recent research of Mitchell (1990), who identified the villas plan's tartan grids, 3 by 3 and 5 by 3 , inspired another direction of analysis of the 19 villas, aimed at 3D parametric reconstruction. For this reason, the grids have been recognized and superimposed on the villas' plans (Fig. 9). Transformations of the grids have been observed and are demonstrated in the drawing. These transformations are divided into several categories: (1) translation, i.e., wall offset; (2) breaking, i.e., cell union; and (3) subdivision, i.e., cell division. Each villa is affected by at least one type of transformation. The resulting schemes are very similar to the ones by Wittkower.

The comparative analysis of the grids in Fig. 9 can reveal some new aspects about the compositional method of Palladio: (1) variants, (2) invariants, (3) recurrences, and (4) exceptions. In some cases, breaking and translation are linked with the results of expanding or reducing the rooms' areas in relation to their function in addition to subdividing to obtain smaller rooms. In villas Cornaro, Pisani in Bagnolo, and La Rotonda, breaking and translation are used for reducing the vestibules' widths so that the path loggia-vestibule-hall undergoes a lateral contraction corresponding with the vestibules. In other cases, the breaking allows, for example, the generation of cross-shaped halls (Malcontenta, Barbaro) and T-shaped halls (Saraceno, Pisani in Bagnolo). In several cases, the three types of transformations affect the staircase whose volume is ruled by many dimensional constraints as defined in Book I. Thus, in villas Thiene, Trissino, 


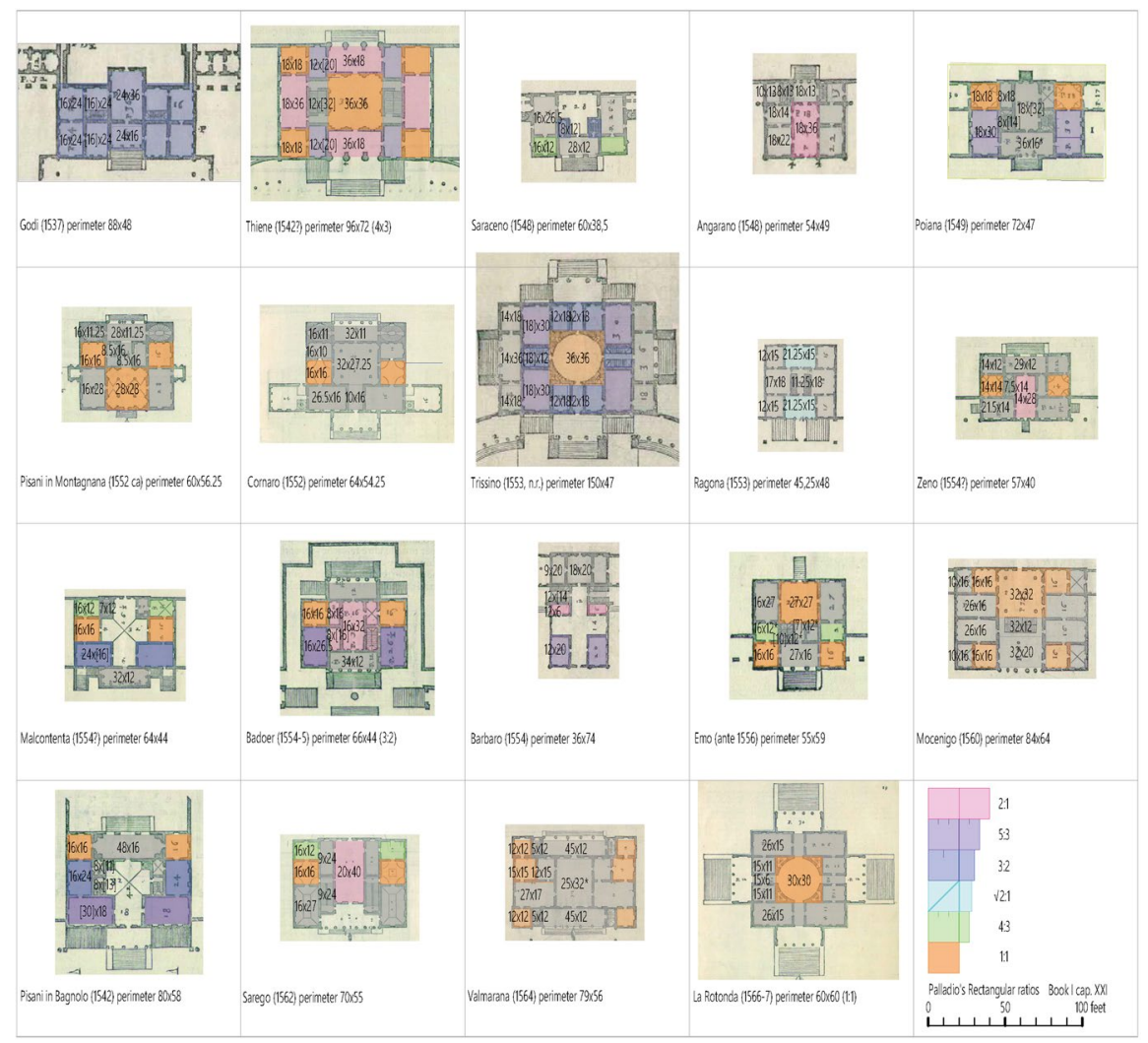

Fig. 6 The six rectangular ratios in the 19 villas. Source: Palladio 1570

Ragona, Mocenigo, Sarego, and Valmarana, the staircases are generated by the combination of breaking and translation; in villas Angarano, Emo, and Pisani in Bagnolo, by the subdivision of the grid. Keeping in mind that the staircase is generally enclosed in a separate room, which became part of the building's grid and that for which Palladio stated that the position had to be established at the beginning of the design process, this element could assume more relevance in the study of compositional rules. Moreover, the staircase is a nodal element in the entrance path that links the horizontal layout of the building with its 3D development. The entrance path, already the subject of the works by Moretti (1952) and Mitchell (1990: 154-167), is now carried out by another comparative plate (Fig. 10) that highlights the entrance sequence in relation to the function of the rooms: (1) loggia, (2) vestibule, (3) hall, and (4) staircase.

For the 3D construction, it must be observed that in a few cases in the text Palladio gives indications regarding the heights of the rooms, and in the elevation drawings, he writes only some essential measurements. It is necessary, therefore, to relate the plans to the elevations and to insert elements, such as orders, vaults, openings, and staircases, keeping in mind the measurements and ratios from Book I. 


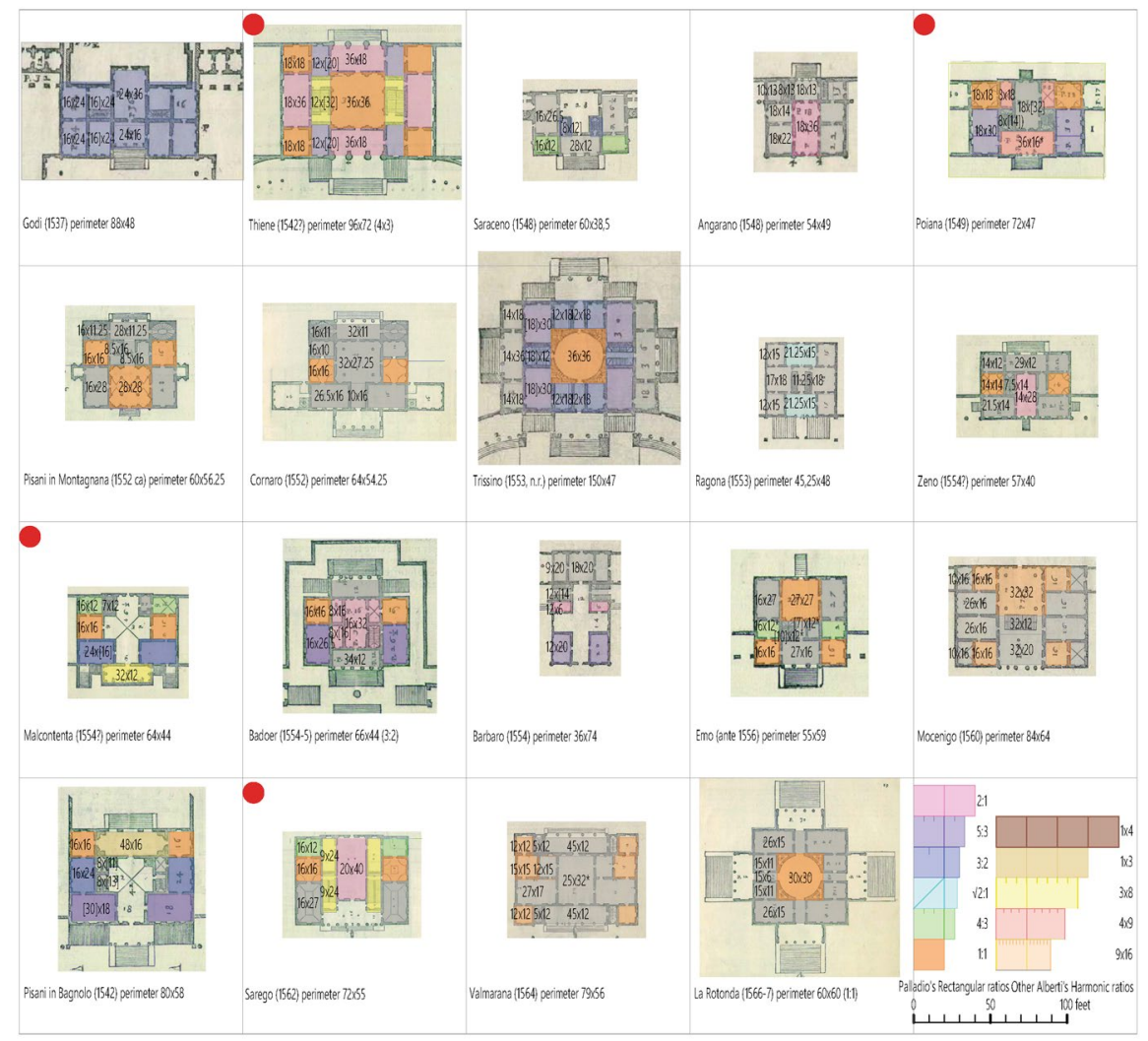

Fig. 7 The six rectangular ratios and the Albertian ratios in the 19 villas. The dot highlights the presence of Albertian ratios. Source: Palladio 1570

Analogous to what was assumed for the analysis of the plans, the ceiling levels were determined by taking the measures given by Palladio and setting them in the middle of the slab thickness after considering their thickness equal to zero.

\section{Parametric Procedures for Creating Parametric Object}

Starting from Stiny and Mitchell's Shape Grammar, the authors first needed to establish an advancement relating to the definition of parametric processes capable of organizing the parametric modeling of 3D space. This is done by considering the coding of walls and slabs among the standard objects, but also of customized objects. The walls and architectural objects are programmed to have adaptive measures to connect to the constraints of the planimetric system and in relation to local and general recurrences found in the treatise. The specific objective is reconstruction of some Palladian villas, and the general objective is establishment of a customized 3D abacus of architectural elements to be used for other reconstructive models. The generation of geometrically 


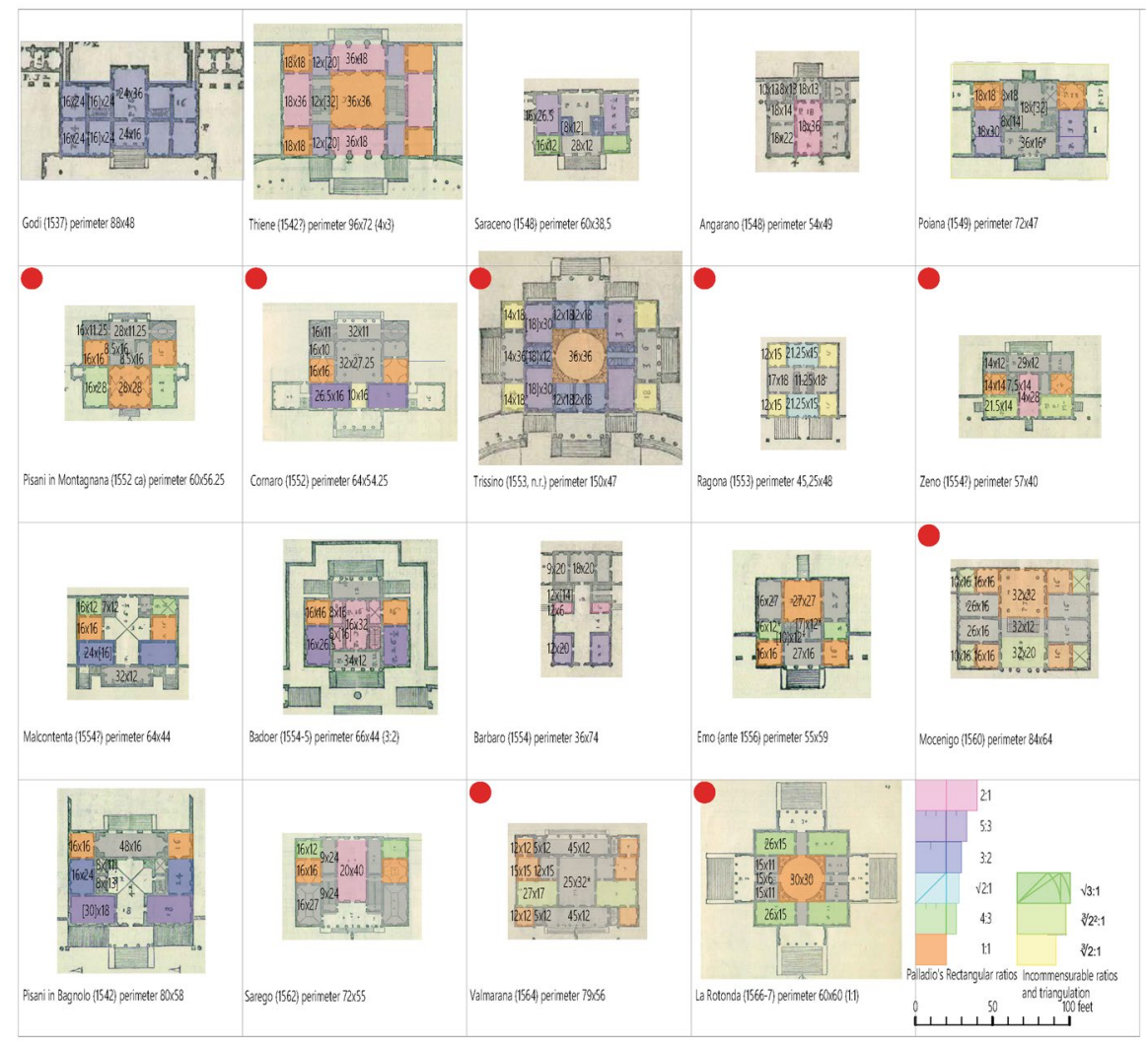

Fig. 8 The six rectangular ratios and the cube-derived ratios in the 19 villas. The dot highlights the presence of cube-derived ratios. Source: Palladio 1570

flexible objects allows for the construction of an abacus of elements that can also be used in historical architecture by implementing the most widely used BIM authoring software and enabling the adoption of HBIM modeling procedures. The procedure that will be exposed will allow the return of the chosen architectures in parametric mode following the ordinary process of BIM modeling: (1) the design of the grids (planimetric layout) and levels (heights), (2) the construction of the walls associated with grids and levels, and (3) finally the introduction of slabs and vaults.

\section{Grids}

For the control of the grid, it has been initially chosen to automate the Shape Grammar rules of Stiny and Mitchell (1978), here revisited in a critical way for the writing of the code in VPL. The operation makes it possible to program generalized automatisms for the construction of the three villas, cataloguing them in families of architectures linked to the 5 by 3 matrix. 


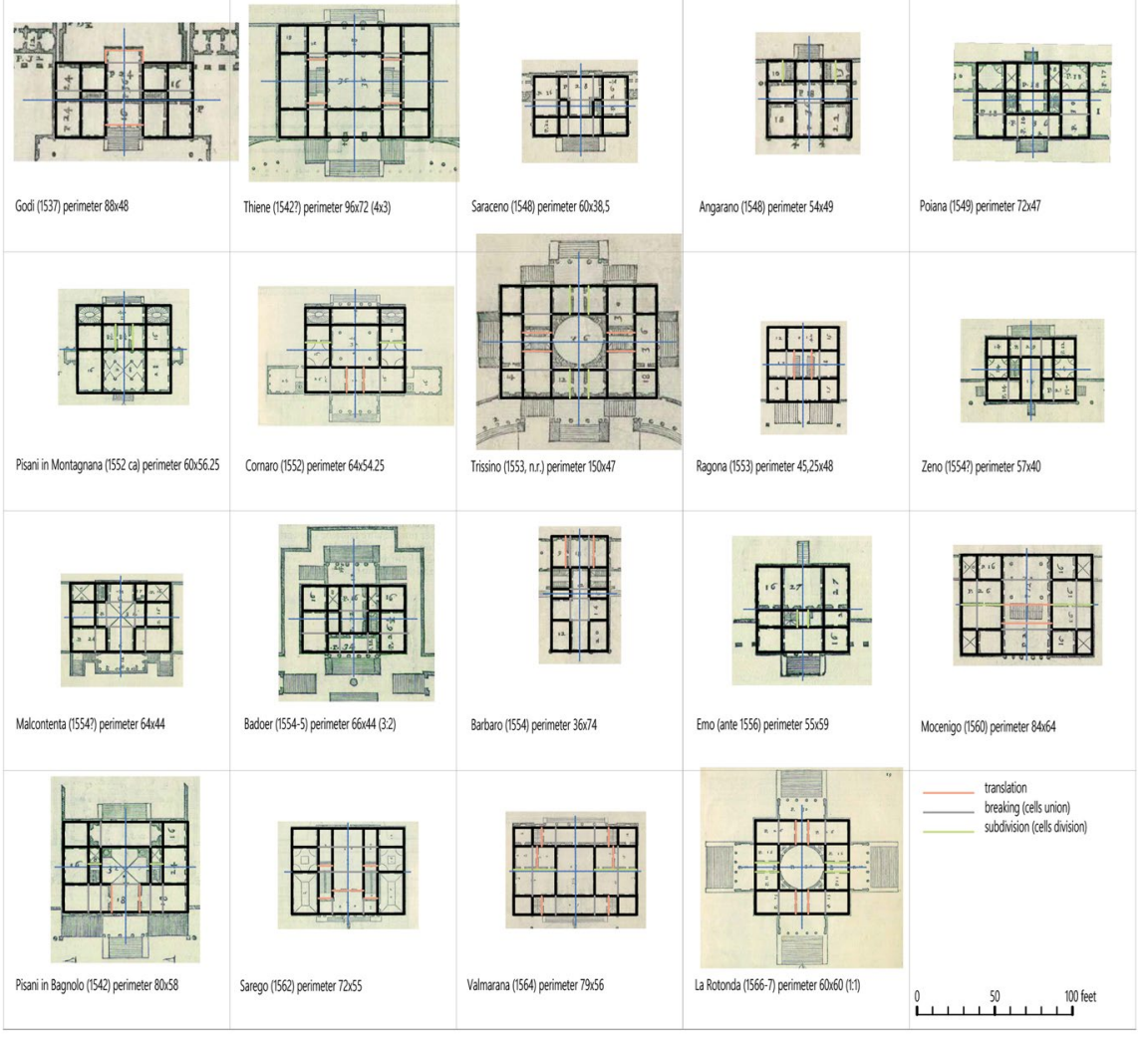

Fig. 9 The villas plan's tartan grids 3 by 3 (red dot) and 5 by 3 (blue dot) and the transformations of the grids: translation (continuous orange line), breaking (dashed gray line), subdivision (continuous green line). Source: Palladio 1570

The construction rules that enrich the algorithm are organized hierarchically in such a way that the first level of construction (grid transformations) influences the subsequent constructions (setting of walls and coverings), passing from a general parametric control (measurements of the grid modules) to a detailed parametric control (thickness of the walls and coverings) (Fig. 11).

Some variations on the construction path concern the axial symmetry of the planimetric system that is guaranteed in the input management phase in the depicted code. The first data introduced are the lists of room dimensions as defined in the plates of Book II. The uniaxial symmetry makes it possible to set up the grid construction algorithm for only half of the system; of the five modules required to define the $\mathrm{X}$ dimension, the two lateral measurements and half the measurement of the central module are entered on a list. In contrast, the sequence of modules along the $Y$ direction is described completely. The first part of the algorithm will be dedicated to restoring the entire matrix of measurements of the tartan grid. While 


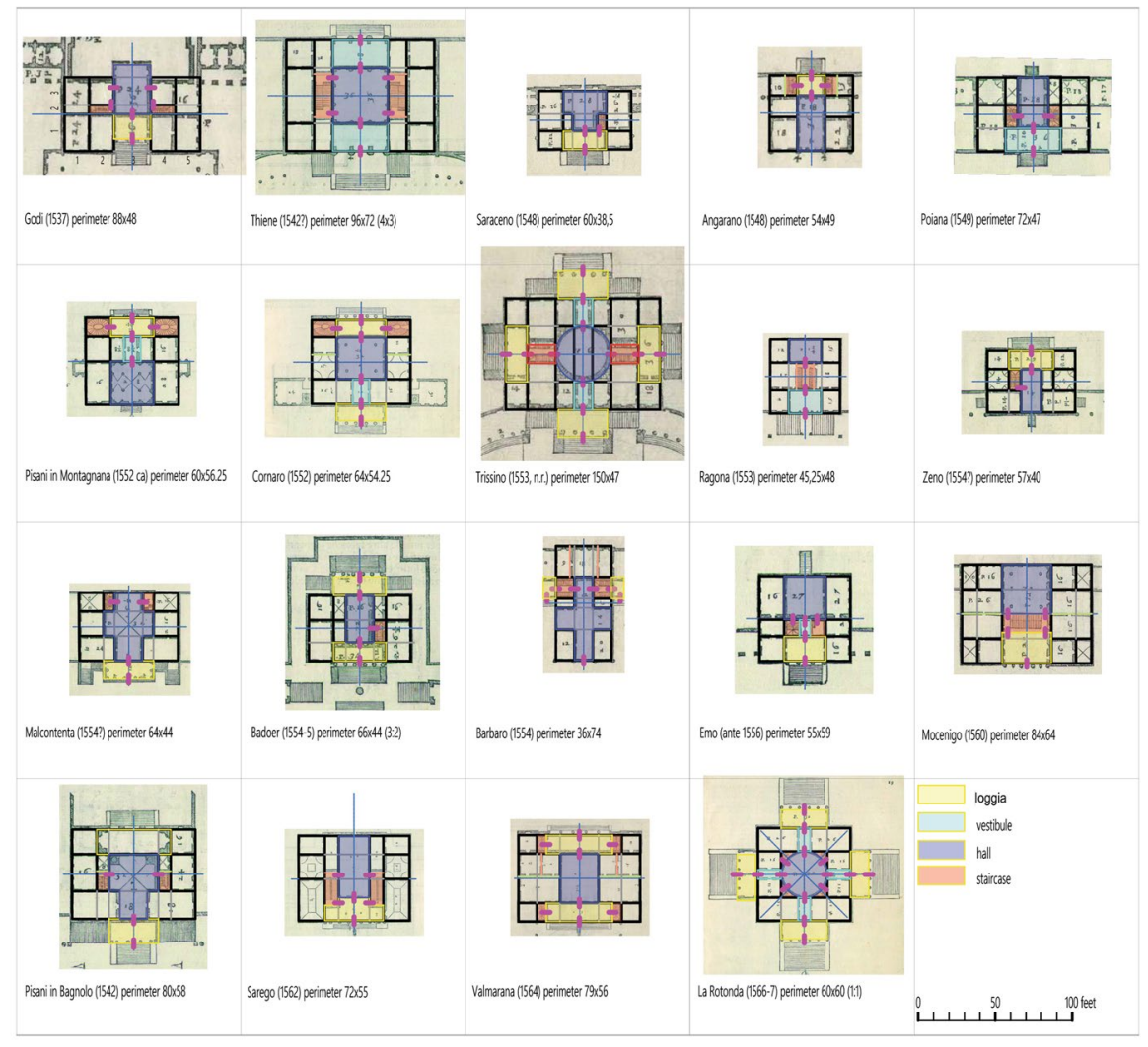

Fig. 10 The entrance path in the 19 villas. Source: Palladio 1570

writing the algorithm in VPL, new nodes of the process are identified that update the algorithm in relation to the tools provided by digital drawing software.

The three villas can be identified as pairs of lists $X, Y$ introduced in the same VPL definition. The relationships between the components that make up the digital algorithm constitute the planimetric family that will return the appropriate grids in output as the inputs change.

The first part of the code in Fig. 12 filters the list of measurements inherent to the selected villa and then divides the process into two flows, with: one relative to the $X$ dimension, to be integrated symmetrically, and the other relative to the $Y$ dimension. The lists of measurements become the coordinates of the vertices of the grid, subsequently structured in rows and columns.

\section{Walls}

The parametric aspects defined in the plan find immediate transposition in the elevation by inserting the walls as additional parametric categories. These entities 
are directly linked to the grid and levels, which give an indication of the position and height of the architectural instances. The internal parameters of the walls (such as thickness) are added to the external constraints determined by the anchorage to the grid axis. The first solution, following Stiny and Mitchell and adding the wall thickness (two feet) to the grid, does not allow us to respect both the few heights given by Palladio and the harmonic ratios investigated in the previous paragraphs. For this reason, the external walls were completely aligned with the outside of the tartan grid while the internal walls were arranged in axis with the lines of the grid. For an effective and complete parametric interpretation of the process, the wall was programmed in VPL to constitute an explicit process that can be fully implemented for greater elasticity and responsiveness of the architectural organism (Fig. 13).

The constructed walls, therefore present a formal instance due to the constraints of collinearity with the previously created grid and an informative instance linked to the technical and graphic characteristics of the type of wall adopted. The programming process provides for a specialization of the grid into border lines and interior lines. To do this, the original grid is transformed into quad-mesh, an entity that distinguishes the border lines (E1) from the interior lines (E2). The boundary lines, merged and suitably simplified (two-point first degree lines), are used for the positioning of the outer walls.

The interior lines that draw the tartan grid are distinguished into horizontal and vertical lines following the criteria of parallelism with the co-ordinate axes constituting two sub-lists of the same list.

The transition from grid to plan is made by intersecting the previous lists with the connection lines between several cells that the rooms occupy in a different way for the three villas. The Boolean process of line selection useful for the design of the final layout was demonstrated to be the center lines of the interior walls. Also, for this second group of lines we proceed by connecting the entities aligned along the same axis by simplifying them into a single line with two control points. This sequence of operations guarantees a good intersection of the walls at the vertices of the grid. The informative characteristics in this phase of the research are reduced to the essential,

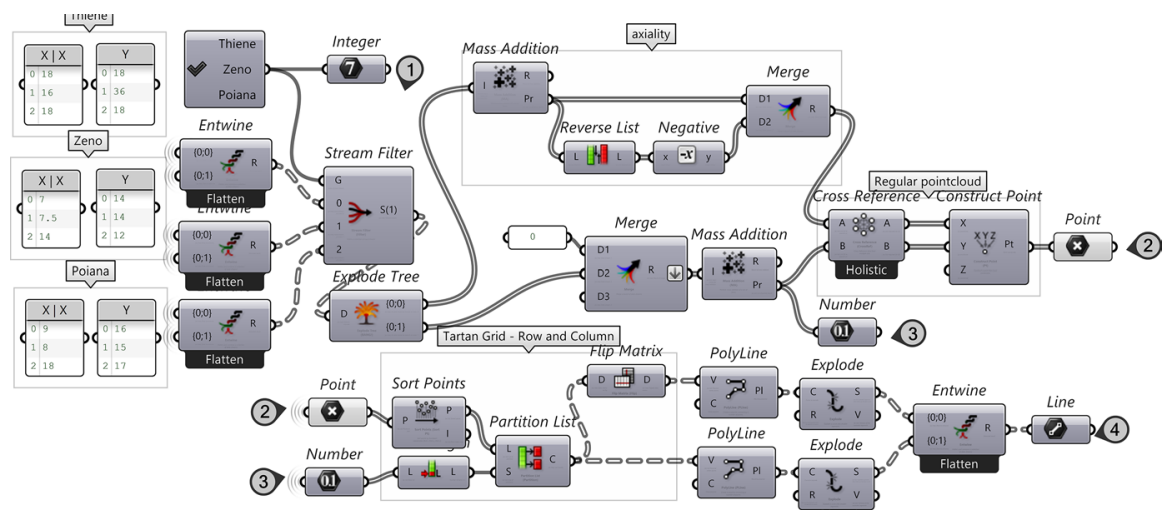

Fig. 11 Visual Programming Language code for the generation of the 5 by 3 tartan grids for Villa Poiana, Villa Zeno, and Villa Thiene 


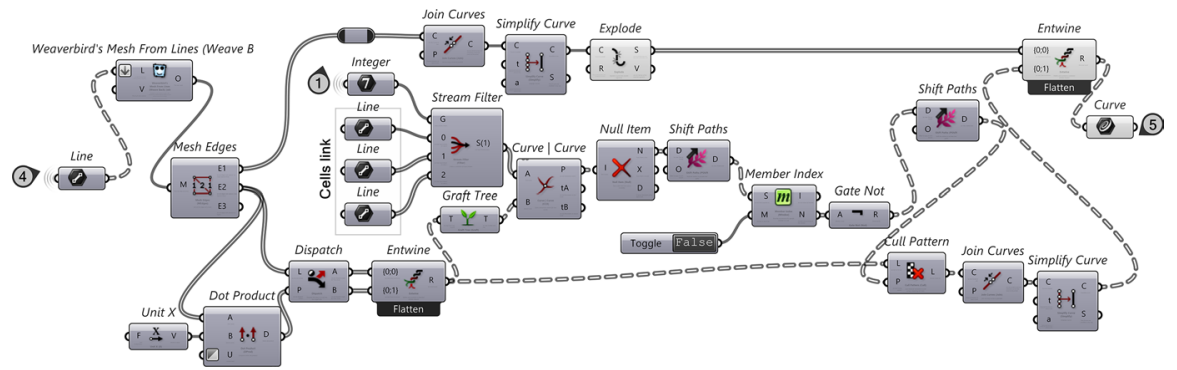

Fig. 12 Visual Programming Language code for the modification of grids through the connection of cells

having adopted a theoretical wall that is two feet thick. However, this second part of the code guarantees the scalability of the operations, implementing the level of detail of the walls.

\section{Vaults}

The villas have recurring typologies of vaults: (1) barrel, (2) coved, (3) cross, (4) sail, and (5) lunette vaults. The vaults are complex families. Their construction is interesting because it allows the set of 3D architectural categories with variable parameters to be enriched. To be able to understand the construction process, the codes capable of returning the parametric features of a selection of vaults recognized in the villas (i.e., cross, coved, and lunettes) are explained hereafter.

The cross vault is an implementation of the barrel (Fig. 14), whereby the opposite segments of the base rectangle become the tracks for the vertical planes where the pairs of generating semicircles are to be constructed. The code was written to constrain

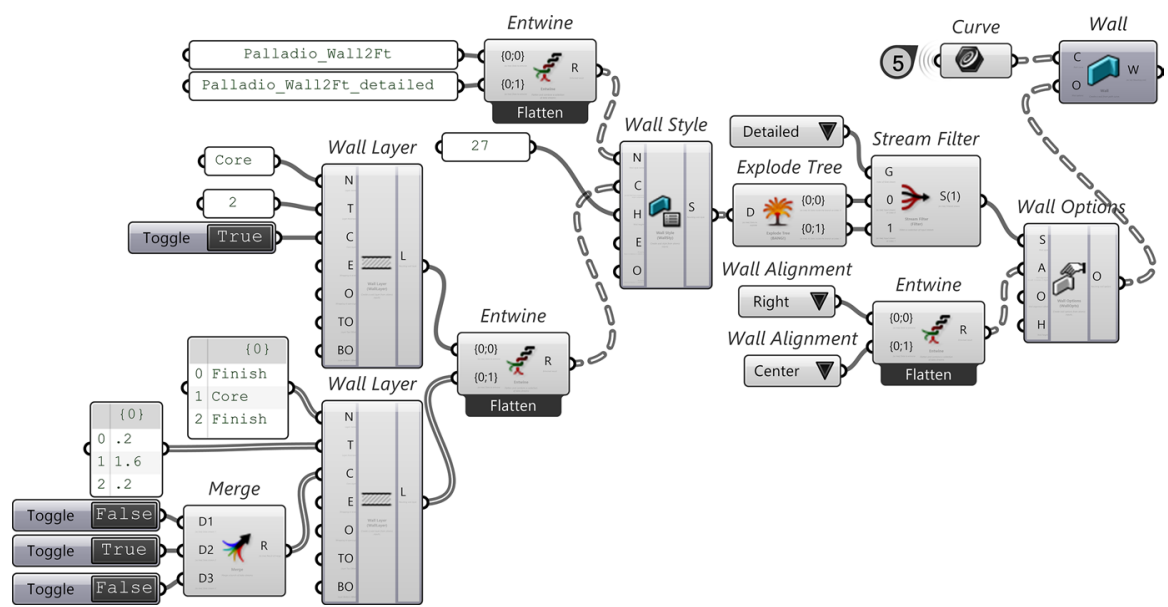

Fig. 13 Visual Programming Language code for changing the level of detail of walls and aligning architectural objects with grid lines 
the size of the diameters to be equal to the measure of the shortest side of the base rectangle. The bottom surface is created by the intersection of the ribbed surfaces generated by the opposite pairs of semicircles. The final solid is the result of the union between the bottom surface and the top surface of the limit parallelepiped and suitably connected by lateral surfaces. The algorithmic process generating the coved vault starts from the base curve of the room to be vaulted.

The procedures for mathematical modeling propose shortcuts for the construction of architectural elements, which is why certain operations generally aimed at solving problems related to product design are useful for making the writing of the code for the representation of the vault more efficient (Fig. 15).

The base polygon is extruded with a height equal to the radius of the arch that generates the cylindrical surfaces of the vault. The parallelepiped generated is filled in along the edges of the upper face of the solid, thus resolving the bottom of the vaulted element. The lunette vault is a coved vault combined with angular lunettes with equal diameters that can be modified using a parameter (Fig. 16).

For one of the four vertices, points are placed along the sides at a distance equal to the size of the diameter established for the lunettes. For each vertex, pairs of points are then identified on the sides that converge in the vertex itself. For these two points, a vertical plane is constructed that intersects the curved edge of the coved vault and provides a new point. For this latter entity and for the midpoints of the neighboring arcs, we construct two lines that will act as the extrusion lines of the respective arcs. This complex procedure is automated in the code and repeated for each vertex, constituting the bottom surface of the adaptive parametric object.

\section{From Elements Parametrization to Villas Reconstruction}

Adding Villa Poiana, Villa Zeno, and Villa Thiene to 5 by 3 tartan grids, it is possible to experiment with the flexible nature of a parametric model based on different plans. This process has an evident influence on the architectural elements as seen regarding the vaults. The latter are widely used in Palladio's architecture and can determine several parameters:

1. local recurrences, whereby they are repeated several times in the same architecture and

2. general recurrences, whereby they are repeated several times in different architectures.

The parameters and relationships used for the $3 \mathrm{D}$ reconstruction of the three villas using the database of adaptive objects are illustrated below. In the three cases the standard and custom architectural elements join together to shape the villas in accordance with the measurements taken from texts and drawings. 


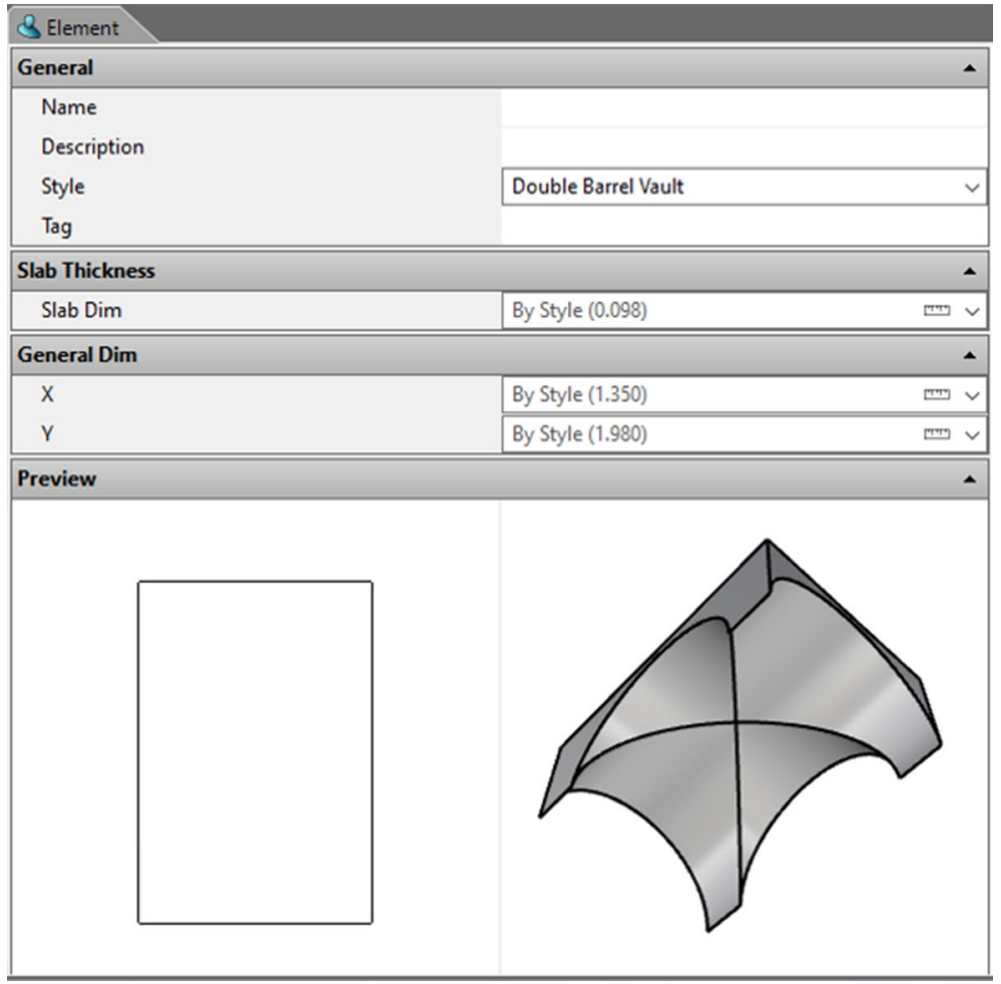

Fig. 14 Windows for changing the parameters of the cross vault. Parametric object stored in the customized database

\section{Villa Poiana}

Describing Villa Poiana in the Vicentino, Palladio says that the large rooms are a square and two-thirds long $(18 \times 30$ feet, in a ratio of $5: 3)$ and vaulted (it is supposed to resemble a barrel), the square ones $(18 \times 18$, in ratio of $1: 1$ although the lateral rooms have a breadth of 17 feet) have lunettes in the corners, and the little rooms have mezzanines. Moreover, the height of the hall is half as great again as the breadth (i.e., $18+18 / 2=27$ feet) and equals the height of the loggia. The hall is barrel-vaulted, and the loggia is cross-vaulted. The elevation drawing gives the height from the ground floor to the cornice, i.e., 30 feet. The plan analysis also reveals the presence of the Albertian ratio (4:9) in the loggia (actually, in the plate the measure of 10 feet for the breadth of the lodge is provided, but the proportions of the drawing lead us reasonably to affirm that the hall has a breadth of 32 and the loggia 16 feet), and the small rooms are crossvaulted. Figure 17 shows the bottom axonometric in which a local recurrence (the cross vaults) is highlighted. 


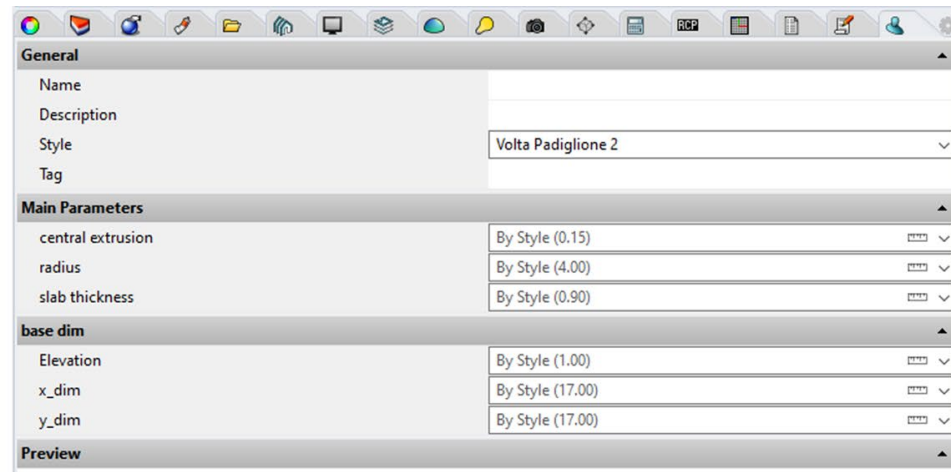

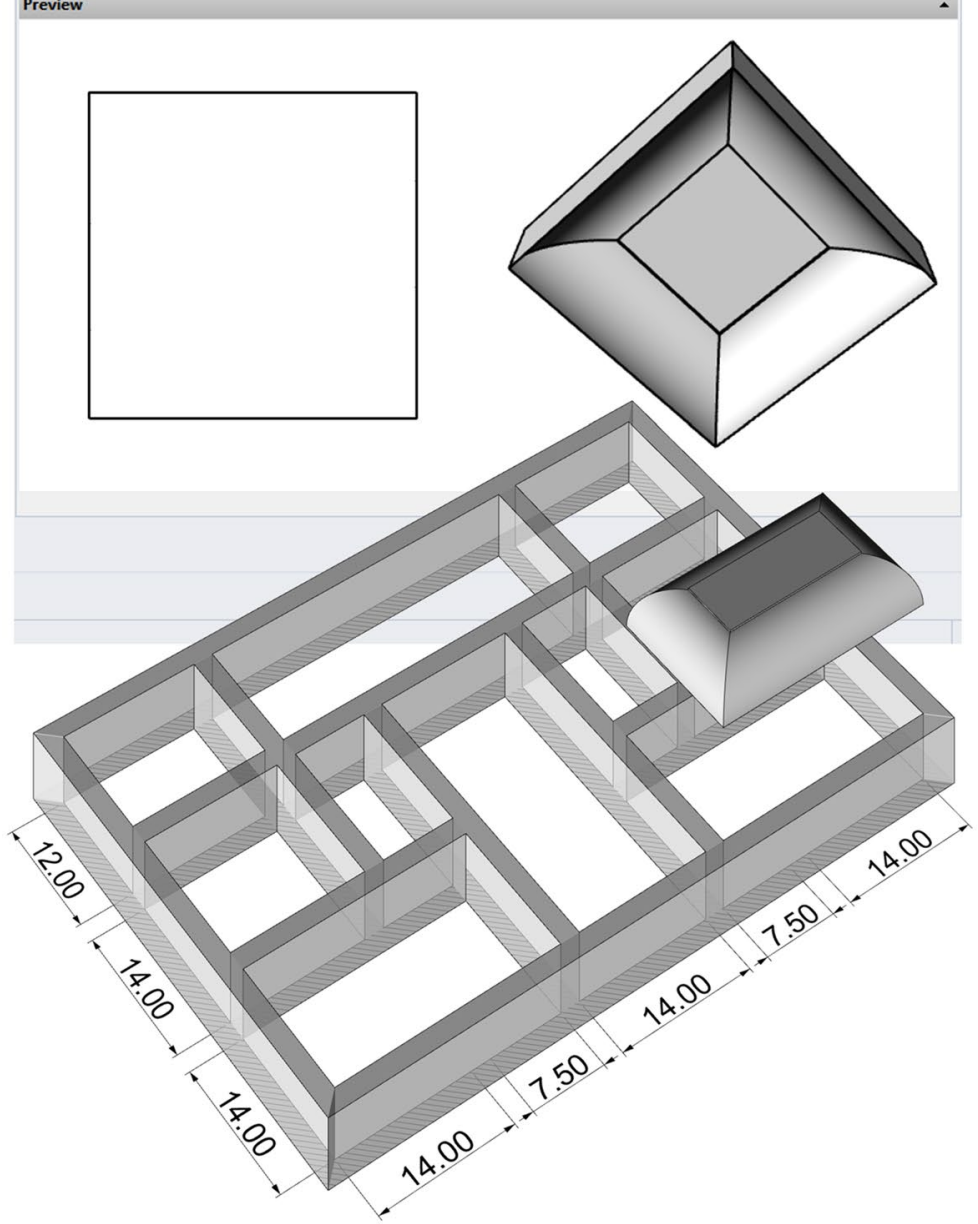

Fig. 15 Above, windows for the parametric variation of the coved vault. Parametric object stored in the customized database. Below, application of the parametric object in the 3D architectural system 


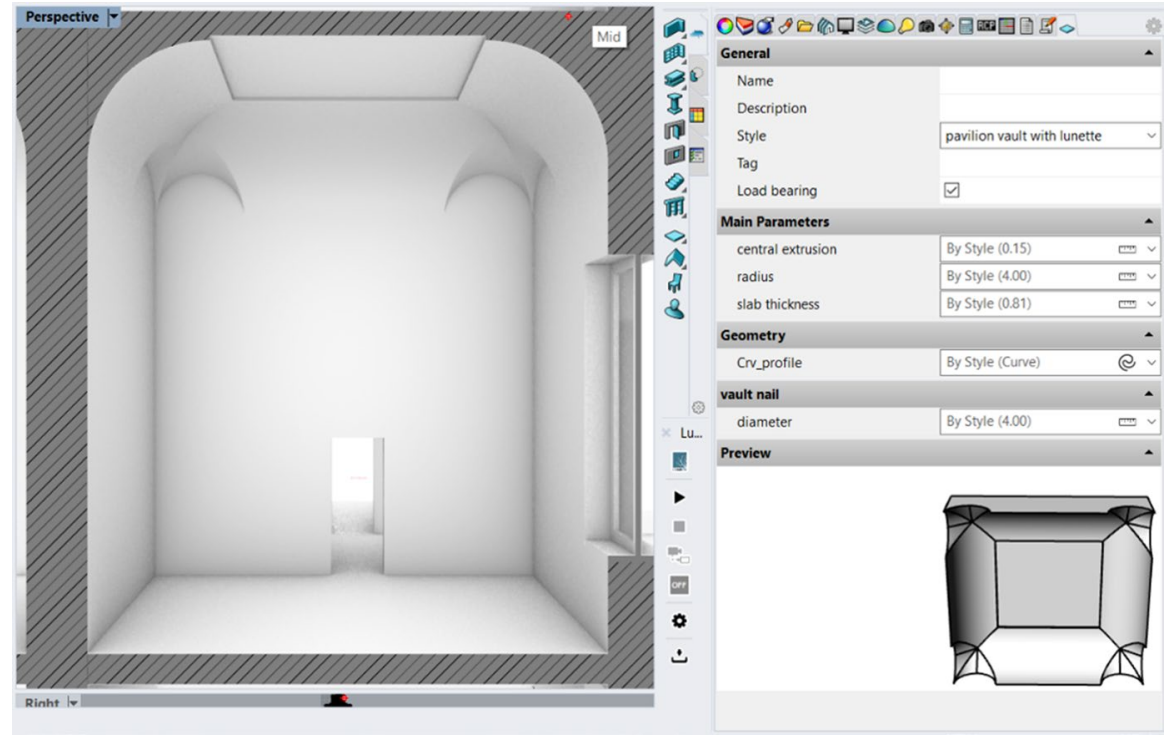

Fig. 16 Right, windows for changing the parameters of the coved vault with lunettes. Parametric object stored in the customized database. Left, application of the parametric object in the $3 \mathrm{D}$ architectural system

The latter is a category present in other villas, and for this reason it also assumes the value of a general recurrence. Barrel, coved, and lunette vaults were adapted and positioned at the surveyed heights. Some special objects, such as the main entrance portal, were also parameterized. This element is repeated inside the villa and on the opposite elevation. In Fig. 18, two perspective sections show the 3D spaces created by positioning the elements according to the parameters initially reported and the enfilades as a result of the juxtaposition of the parts (Fig. 18).

\section{Villa Zeno}

Villa Zeno at Cessalto in the text of Palladio has all vaulted ground floor rooms. Moreover, Palladio says that the height of the vaults of the larger rooms $(21.5 \times 14$ feet $)$ was set according to the second method for fixing vault heights, namely, the geometric one. For this reason, these rooms' barrel-vaults, should be about 17.35 feet high. The square rooms $(14 \times 14$ feet, in ratio $1: 1)$ have lunettes in the corners, the little rooms $(14 \times 12$ feet $)$ are barrel- vaulted, the hall $(14 \times 28$ feet, in ratio $2: 1$ ) and the loggia have the same height and exceed the height of the rooms. It should still be noted, using a rough approximation, the cube-

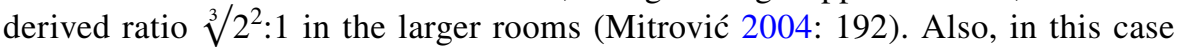
Palladio provides the height from the ground floor plan to the cornice ( 27 feet). The view from below of the horizontal section (Fig. 19) shows the complexity of the roofing on the ground floor and a typical form for setting the parameters 


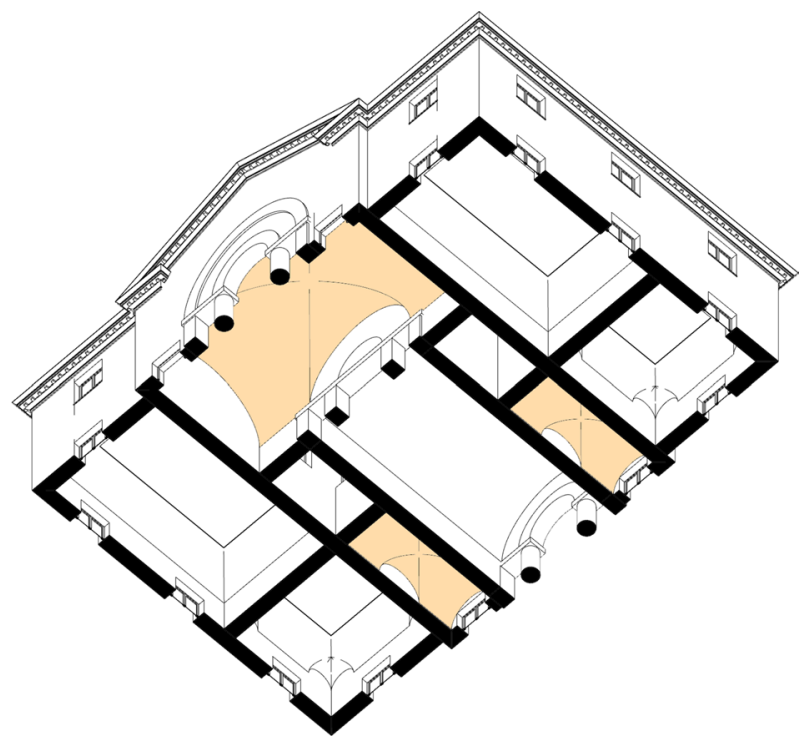

Fig. 17 Axonometric cross-section seen from below of Villa Poiana

of the new adaptive architectural object (the coved vault). Also, in this case the horizontal and vertical perspective section of the entire model (Fig. 20) illustrates the $3 \mathrm{D}$ spaces according to the treatise and to visualize the enfilade.

\section{Villa Thiene}

Villa Thiene in Cicogna proposes a complex articulation of the rooms' roofs on the ground floor (Fig. 21). The central square hall $(36 \times 36$ feet, that is in a ratio of $1: 1)$ is double-height cross-vaulted, while the large rooms $(18 \times 36 \mathrm{feet}$, in a ratio of $2: 1)$ have coved vaults. The square rooms at the corners $(18 \times 18$ feet, in ratio 1:1) are covered with sail vaults, and the small rooms $(12 \times 20$ feet, in a ratio of 5:3) have mezzanines covered with flat slabs. The breadth of the small rooms (20 feet) has been derived from the wall alignments and proportions of the drawing. Similarly, the breadth of the staircases (32 feet) has been determined: it presents an Albertian ratio of 3:8. In the elevation, the height from ground floor to main cornice is 40 feet and the height from ground floor to first floor cornice is 25 feet. The relationship between interior and exterior defined by the cornice, the external loggias, the doors, and windows allows the positioning of vaults and slabs, providing the spatiality visible in the perspective section (Fig. 22); the perspective section of the plan once again shows the enfilade.

Villa Thiene has imposed the design of new parametric categories that enrich the three-dimensional database, namely, the architectural orders are represented in the model with a level of detail comparable to the representation scale of 1:50; in 


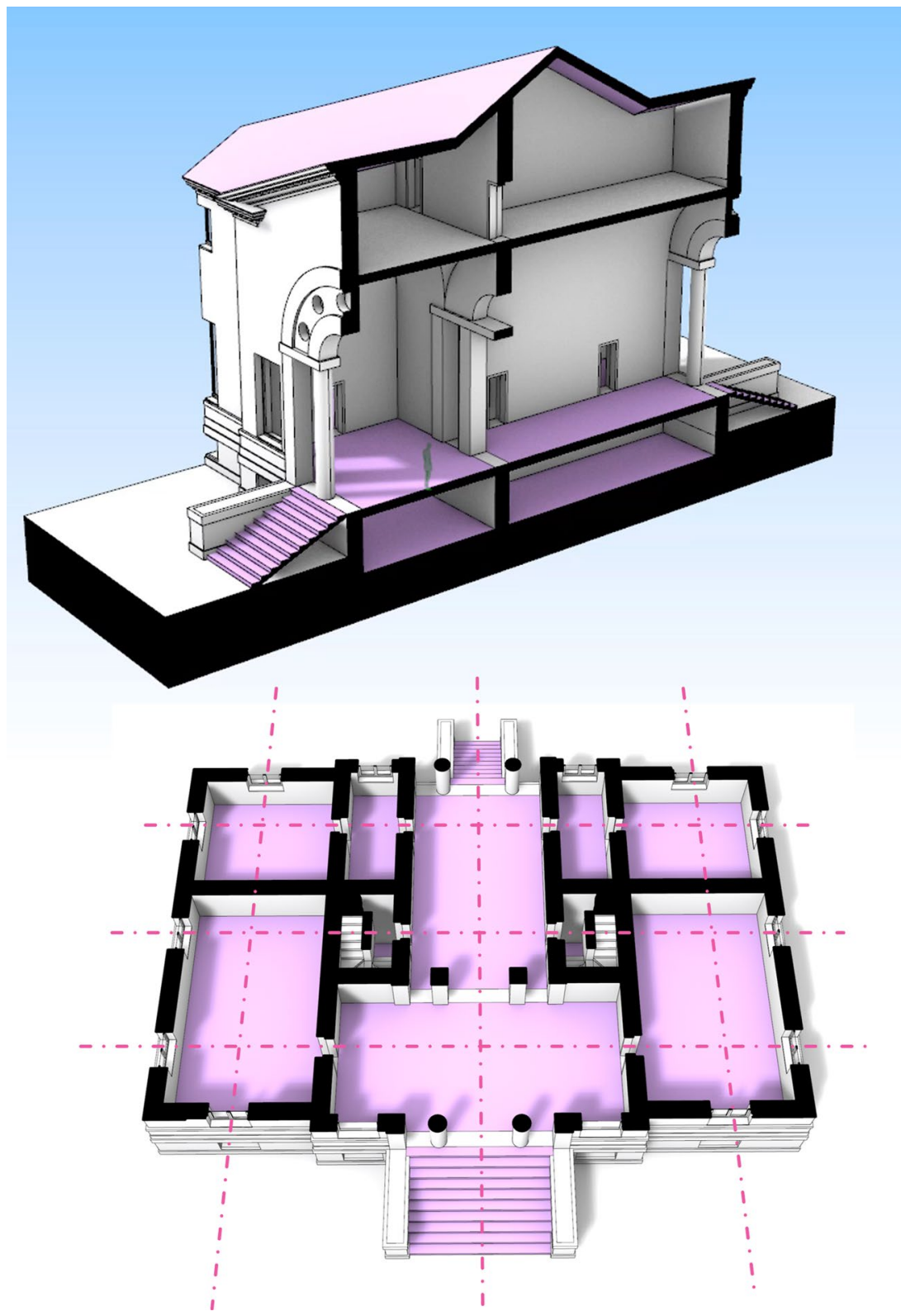

Fig. 18 Vertical perspective section and horizontal perspective section of Villa Poiana

addition to the base, shaft. and capital of the column, new architectural categories, such as cornices and balustrades, were generated. 


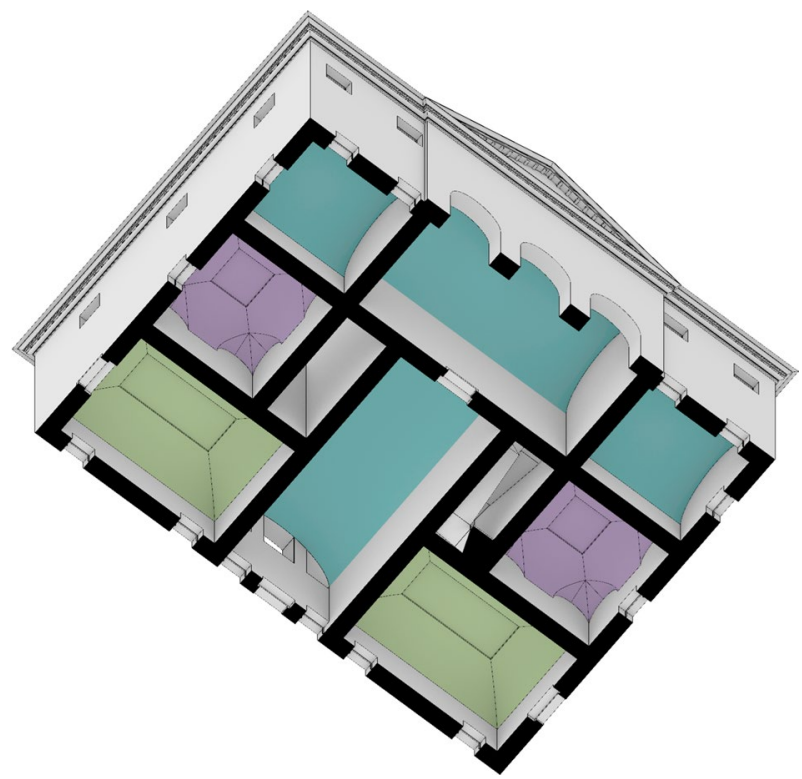

Fig. 19 Axonometric cross-section seen from below of Villa Zeno

\section{Conclusion}

March reminds us that Palladio was a mannerist and that at his time rules "were there to be challenged, to be transformed, to surprise in their unexpected application, or unforeseen consequence. In the process of design, as the dimensions of a work gather around the physical and geometric possibilities and constraints, the designer discerns familiar patterns and potential interpretations" (March 2001: 101). It is well-known that Palladio's treatise does not contain all necessary information for fully reconstructing each villa. At the current phase of the research, the authors have organized a dynamic planimetric grid and an assembly kit of 3D architectural elements useful for combining knowledge data and testing their consistencies. Moreover, the developed instrument could become an experimental laboratory in which different hypotheses of integration by the authors, or other scholars with reference to the sources, could be tested. The inclusion of other case studies could deepen the knowledge of compositional logic by highlighting the rules of combination of room functions, shapes, ratios, and that of their elements.

The fully developed case studies (Villa Poiana, Villa Thiene in Cicogna, and Villa Zeno) of three villas characterized by uniaxial plans and 5 by 3 grids (the most recurrent in Palladio's villas) have achieved the objectives of the present research, allowing an elementary representation of the villa's parametric model through a related system of signs and texts. The results of this phase of the research follow a specific plan: (1) the recognition of typological and morphological variants and invariants, (2) the setting of planimetric tartan grids 


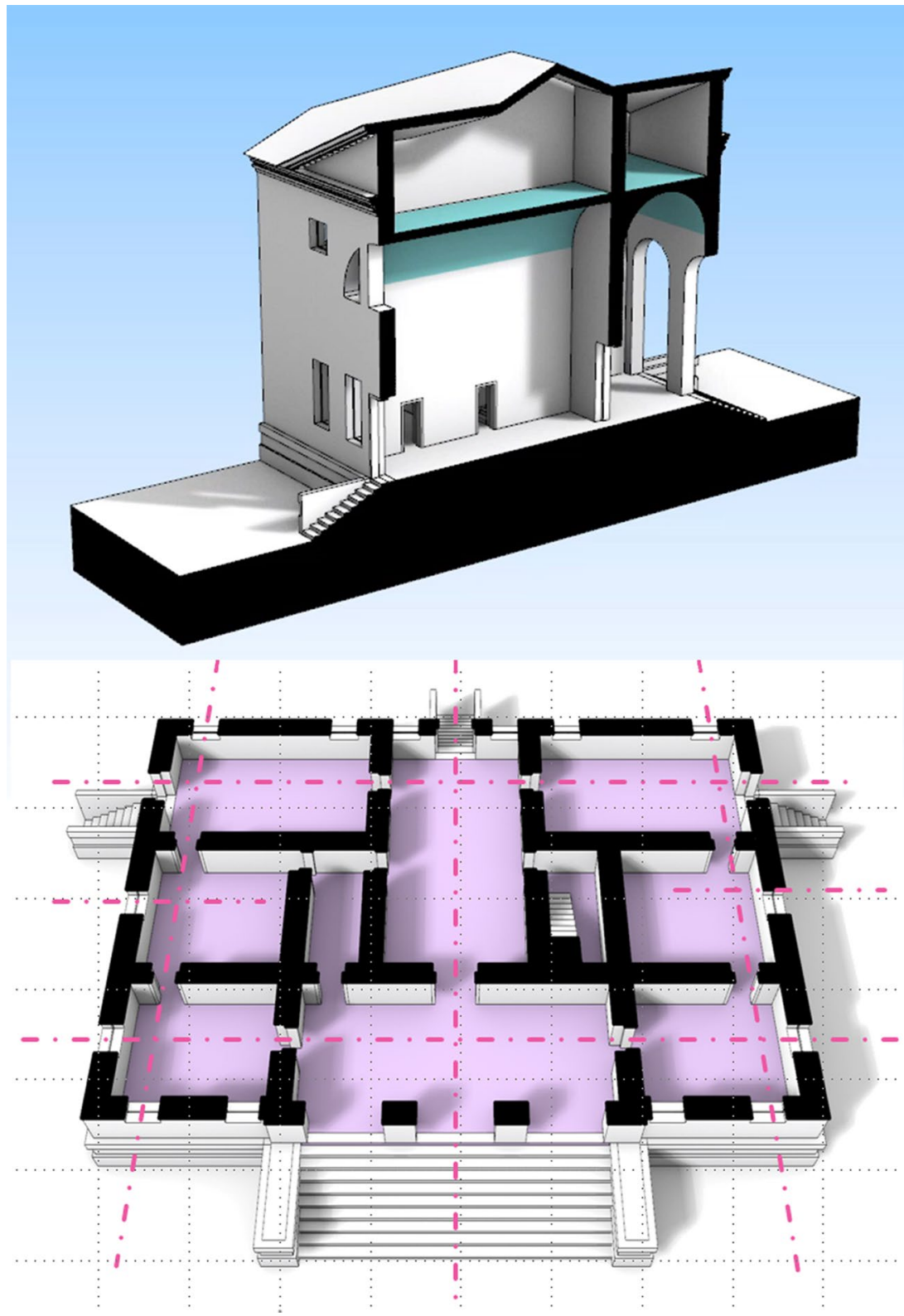

Fig. 20 Vertical perspective section and horizontal perspective section of Villa Zeno

which are dynamically transformable, (3) the creation of families of architectural elements defined parametrically, and (4) the scalability of the process on other Palladian villas. Future research developments concern the test of the 


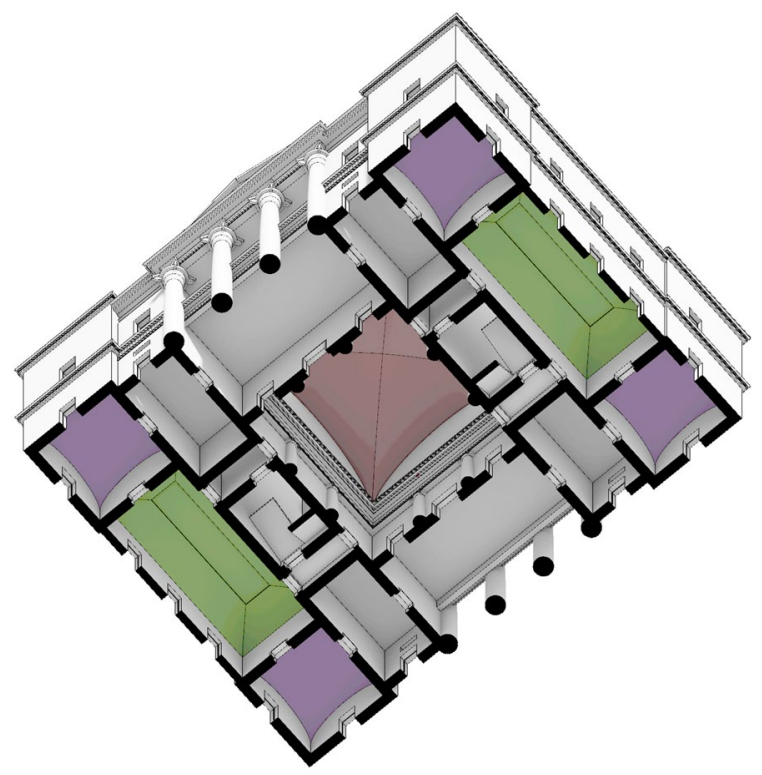

Fig. 21 Axonometric cross-section seen from below of Villa Thiene

methodology set up in this research on 3 by 3 grids for the villas and the passage from uniaxial plan to radial plan.

Acknowledgements This paper is the result of research conducted jointly by the two authors, who wrote the paragraphs as follows: R. Spallone Introduction, Architectural Principles and Compositional Criteria in Book I, Room Ratios in the Villas, Plan Grids from 2D Compositional Rules to 3D Design; M. Calvano Parametric Procedures for Creating Parametric Object, From Elements Parametrization to Villas Reconstruction; Spallone and Calvano Conclusion. The figures have been edited as follows: Fig. 2 drawing: R. Spallone; Figs. 5, 6, 7, 8, 9, 10 graphic overlay: R. Spallone; Figs. 11, 12, 13, 14 coding: M. Calvano; Figs. 15, 16 coding and 3D parametric modelling: M. Calvano; Figs. 17, 18, 19, 20, 21, 22 parametric modelling: M. Calvano.

Open Access This article is licensed under a Creative Commons Attribution 4.0 International License, which permits use, sharing, adaptation, distribution and reproduction in any medium or format, as long as you give appropriate credit to the original author(s) and the source, provide a link to the Creative Commons licence, and indicate if changes were made. The images or other third party material in this article are included in the article's Creative Commons licence, unless indicated otherwise in a credit line to the material. If material is not included in the article's Creative Commons licence and your intended use is not permitted by statutory regulation or exceeds the permitted use, you will need to obtain 


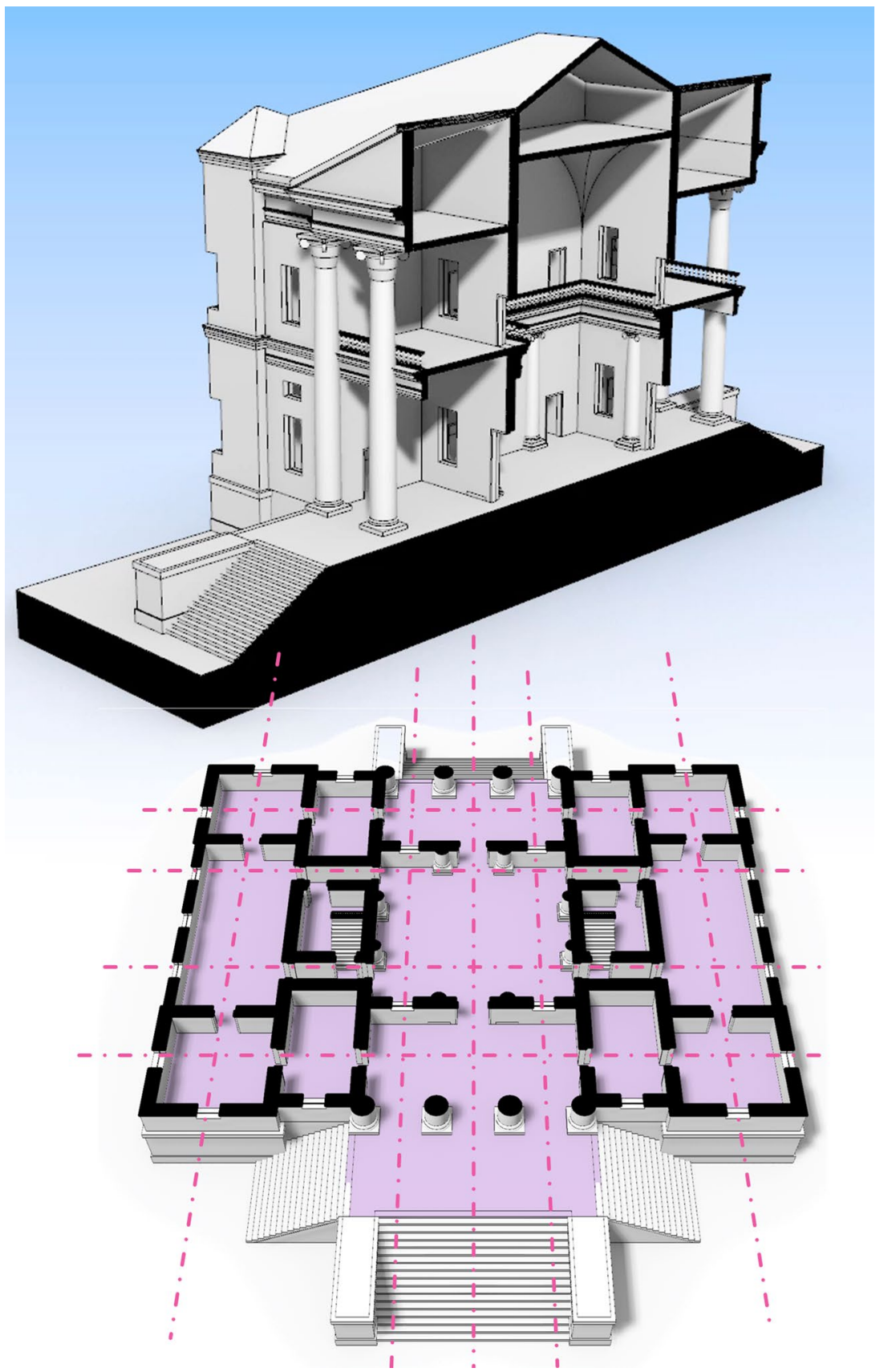

Fig. 22 Vertical perspective section and horizontal perspective section of Villa Thiene

permission directly from the copyright holder. To view a copy of this licence, visit http://creativeco mmons.org/licenses/by/4.0/. 


\section{References}

Benelli, Francesco. 2008. Rudolf Wittkower studioso delle ville di Palladio. In Palladio 1508-2008. Il Simposio del cinquecentenario, ed. Guido Beltramini and Howard Burns, 49-53. Venice: Marsilio.

García-Salgado, Tomás. 2008. A Perspective analysis of the proportions of Palladio's Villa Rotonda: making the invisible visible. Nexus Network Journal 10(2): 269-282.

Howard, Deborah, and Longair, Malcom. 1982. Harmonic proportion and Palladio's "Quattro Libri". Journal of the Society of Architectural Historians 41(2): 116-143.

Kühbacher, Sabine. 1990. Il principio della corrispondenza nell'architettura del Serlio e del Palladio. In Andrea Palladio: nuovi contributi, ed. André Chastel and Renato Cevese, 166-181. Milan: Electa.

March, Lionel. 2001. Palladio's Villa Emo: the golden proportion hypothesis rebutted. Nexus Network Journal 3(2): 85-104.

Mitchell, William J. 1990. The logic of architecture: design, computation, and cognition. Cambridge, Massachusetts: MIT Press.

Mitrović, Branko. 1990. Palladio's theory of proportions and the second book of the Quattro Libri dell'Architettura. Journal of the Society of Architectural Historians 49: 279-292.

Mitrović, Branko. 2004. Learning from Palladio. New York: Norton \& Company.

Moretti, Luigi. 1952. Strutture e sequenze di spazi. Spazio IV(7): 9-20, 107-108.

Palladio, Andrea. 1570. I quattro libri dell'architettura. Venice: de Franceschi.

Palladio, Andrea. 1997. The four books on Architecture. Translated by Robert Tavernor and Richard Schofield. London: The MIT Press.

Rosci, Marco. 1966. Il trattato di architettura di Sebastiano Serlio. Milan: I.T.E.C.

Sass, Larry. 2001. Reconstructing Palladio's villas: a computational analysis of Palladio's villa design and construction process. In Reinventing the discourse - how digital tools help bridge and transform research, education and practice in Architecture, Proceedings of the twenty-first annual conference of the Association for Computer-Aided Design in Architecture (ACADIA), Buffalo NY, 11-14 October 2001, 212-226.

Spallone, Roberta, and Calvano, Michele. 2019. Roots of 'parametric thinking' in Palladio's Villas. Surveying, interpreting and visual programming the plates from I quattro libri di Architettura. In Metrology for Archaeology and Cultural Heritage, Proceedings of the International Conference MetroArchaeo, Florence, Italy, 4-6 December 2019, 217-222.

Stiny, George, and Mitchell, William J. 1978. The Palladian grammar. Environment and Planning B 5: 5-18.

Tikhonova, Olha. 2019. New approach to proportional analysis of Palladio's designs in Book II with particular attention to loggias. Nexus Network Journal 21: 359-381.

Wassell, Stephen R. 1999. The mathematics of Palladio's villas: Workshop '98. Nexus Network Journal 1: 121-128.

Wittkower, Rudolph. 1944. Principles of Palladio's architecture: I. Journal of the Warburg and Courtauld Institutes 7: 102-122.

Wittkower, Rudolph. 1945. Principles of Palladio's architecture: II. Journal of the Warburg and Courtauld Institutes. 8: 68-106.

Wittkower, Rudolph. 1949. Architectural principles in the age of humanism. London: Warburg Institute.

Publisher's Note Springer Nature remains neutral with regard to jurisdictional claims in published maps and institutional affiliations.

Roberta Spallone architect and Ph.D. in "Drawing and Survey of Architectural Heritage", is Full Professor at the Politecnico di Torino, Department of Architecture and Design (DAD). She is a member of the School of Architecture, and currently teaches in the Laboratory of Drawing and Survey and Digital Techniques of Representation. She is on the Board of the Doctorate of Architectural and Landscape Heritage and has been director of the excellence Ph.D. course "Complex vaulted systems: geometry, design, construction". Her research focusses on the fields of history and criticism of architectural drawing, with particular attention to classic treatises on architecture and the art of fortification, and digital technologies for graphical analyses and reconstructive modeling. She is author of over 200 publications, including both monographs and articles, and has participated as a speaker in many international conferences, including Nexus conferences in 2016, 2018, and 2021. 
Michele Calvano is an architect, PhD in Sciences of Representation, research fellow at ISPC - CNR and in the past at DAD of Politecnico di Torino; specialised in mathematical and parametric modelling. He has written articles and books on reverse modelling, shape design, digital representation of architecture and urban space also using BIM procedures. He has taught at the Sapienza University of Rome, the Politecnico di Torino and the University of Camerino (SAD). He currently teaches at the Polytechnic of Milan in the School of Design and the Academy of Arts and New Technologies in Rome (AANT). He collaborated with companies active in the AEC field to support them in the engineering of complex shapes. 